\title{
Elementar: Antonio Candido, inventor do inventivo Sérgio Buarque de Holanda'
}

\author{
Vinícius Madureira Maia* \\ https://orcid.org/0000-0001-5301-0155 \\ Kadma Marques Rodrigues* * \\ https://orcid.org/0000-0002-7310-958X
}

O páthos da amizade

Sérgio Buarque de Holanda talvez pudesse dizer de si aquilo que Conan Doyle pôs certa vez na boca de seu mais célebre personagem, o detetive Sherlock Holmes, a respeito de seu assistente e braço direito, dr. John H. Watson, quando, novamente reunidos no endereço da 221B Baker Street, andavam prestes a apurar o que seria um escândalo na Boêmia: "Eu estaria perdido sem meu Boswell". A referência invulgarmente afetuosa a um dos maiores diaristas do século XVIII, o nobre escocês James Boswell, reconhecido pela autoria de uma entusiástica biografia de seu amigo Samuel Johnson - tida como a mais distinta obra de arte biográfica em todo o domínio da literatura inglesa (Bate, 1977, p. XIX) - talvez possa também convir à pessoa de Antonio Candido.

Na maior parte das estórias de sir Arthur, coube a Watson narrar as façanhas investigativas de seu amigo Holmes. E, de resto, conhecer uma pessoa ou personagem por intermédio de um seu amigo ou ente próximo nunca parece empresa ou método de todo confiáveis. Quanto a isso, o próprio Holmes se mostrava ambivalente, ora envaidecido, ora relutante, face às tinturas românticas que Watson calha de deitar

- Universidade de São Paulo, São Paulo, Brasil.

* Universidade Estadual do Ceará, Ceará, Brasil.

1. Agradeço aos professores Leopoldo Waizbort, Sérgio da Mata e Pedro Meira Monteiro a leitura prévia deste trabalho, por cujos eventuais equívocos não têm qualquer responsabilidade. 
naquelas suas experiências conjuntas de detecção, que se queriam, antes, sérias, sóbrias, desprovidas de emoções, conforme o desejo do grave detetive.

O deslumbramento da amizade parece ser, no entanto, um páthos corriqueiro na história literária. Em uma recensão de Kafka: eine Biographie, primeira biografia dedicada ao escritor tcheco, em 1937, por seu amigo Max Brod, Walter Benjamin ([1938] 2002, pp. 317-319) deplora a atitude do autor, a sua "mais perfeita bonomia", que chega a contradizer a tese mesma do livro: a de que Kafka teria encontrado "a si mesmo no caminho da solidão”. Nesse mote, Benjamin entrevê apenas as marcas do desmazelo jornalístico e os floreios do beletrismo, tamanha a falta de distância entre Brod e o seu objeto, bem como a ausência de qualquer senso de rigor pragmático que se demanda de uma obra inaugural do tipo. Perante a "santidade" de Kafka, revelando intimidade típica de um devoto, Brod excederia os limites da moderação nas homenagens que lhe rende e na familiaridade do tratamento que lhe dispensa. Benjamin então recorda que o convívio cerrado com a figura dos santos tem um assento especial na história religiosa, sobretudo com o pietismo; em outras palavras: essa aventada proximidade seria a atitude mais obscena que se possa imaginar em um intelectual.

$\mathrm{Na}$ economia das proposições de Antonio Candido sobre Sérgio Buarque, não se pode perder de vista que, em grande maioria, são concepções debuxadas por um seu grande, longevo amigo. De sorte que participam não apenas do que é peculiar ao gênio crítico de Antonio Candido, mas também do que é próprio de tais relações.

\section{O princípio da philia}

Apesar de se encontrarem em Berlim ao mesmo tempo e terem até residido algo próximos um do outro, em 1929, ambos se conheceram somente nos idos de 1943; Sérgio contava já quarenta e um anos de idade, e Antonio Candido, então com vinte e cinco, nele já enxergava "um mestre incomparável." A oportunidade de convívio se deparou maior a partir da inauguração, em São Paulo, da Livraria e Editora Brasiliense - sob a égide de Caio Graco Prado e Caio Prado Júnior, associados a Monteiro Lobato, Artur Neves, Maria José Dupré e outros -, com o lançamento do primeiro livro editado do jurista Hermes Lima, a cuja solenidade muitos intelectuais cariocas acorreram. O ano era 1944, segundo o velho crítico², e Sérgio Buarque, que também se fez presente, embora ainda residisse no Rio de Janeiro nessa época, aproveitava a ocasião para assinar autógrafos em exemplares de seu recente Cobra de vidro - que

\footnotetext{
2. Hermes Lima lançou pela Brasiliense Notas à vida brasileira, mas não em 1944, conforme as memórias
} de Antonio Candido, e, sim, no ano seguinte (Lima, 1945). 
Candido resenhara, por sinal, em agosto daquele ano para a revista Clima -, saído pela Livraria Martins, editora paulistana fundada por um amigo em comum, José de Barros Martins, por cujo intermédio viria também a lume o livro Introdução ao método crítico de Silvio Romero um ano depois. Admira tenha guardado desse contato rápido uma impressão forte da personalidade de Sérgio Buarque, tomado que foi "pela sua naturalidade, despretensão, ausência de dogmatismo" em "um ensaísta que era também um pensador" (Candido, 1983, p. 132).

A Sérgio, Candido pôde revê-lo meses depois, mais precisamente em 22 de janeiro de 1945, quando do "memorável" Primeiro Congresso Brasileiro de Escritores, realizado no Teatro Municipal de São Paulo sob a presidência de Aníbal de Machado e a coordenação de Sérgio Milliet, "uma experiência incrível para todos nós, jovens e maduros, pela unidade obtida sobre tantas divergências na arregimentação dos intelectuais contra o Estado Novo" (1983, p. 132). Candido alude aí ao momento de rara coesão entre intelectuais das mais variegadas vinculações institucionais e políticas - católicos, comunistas, liberais, socialistas, luminares da literatura e do pensamento social e jurídico -, oriundos dos vinte e um estados do Brasil de então, ao lado de representantes de dezesseis países, de cujo exercício de conciliação no incipiente campo cultural brasileiro exsurgiu, próximo ao fim da Terceira República, uma declaração de princípios em prol da legalidade e da realização de eleições livres e diretas, publicada tão somente no dia 4 de março daquele ano, devido às imposições da censura aos órgãos da imprensa.

A década de 1940 lhe será repleta de Sérgio Buarque de Holanda. É ainda em 1945 que aparece Monções, o qual "mostrava um outro lado dele", não o do ensaísta, mas decerto o do "historiador apaixonado pela cultura material". É Monções, ao lado de Índios e mamelucos na expansão paulista, que segue elencado por Antonio Candido entre as prestigiosas influências intelectuais - Audrey Richards, Claude Lévi-Strauss, Karl Marx, Robert Redfield, por exemplo - atuantes sobre a pesquisa que lhe valerá a tese de doutorado, intitulada Os parceiros do Rio Bonito (1954) e publicada como livro homônimo, sem maiores retoques, uma década depois. Em dedicatória constante no exemplar da segunda edição de Osparceiros do Rio Bonito destinado a Sérgio Buarque, hoje pertencente ao acervo deste último, abrigado na Unicamp, leem-se as seguintes linhas penhoradas:

Caro Sérgio: relendo este livro para a correção de provas, fiquei impressionado ao ver o quanto ele é influenciado pela sua obra, sobretudo Bandeirantes e mamelucos e Monções. Eu já sabia disso, é claro, e o digo no prefácio; mas a impregnação é maior do que eu pensava. A culpa não é sua. Mas o que ele tiver de aproveitável será devido a isto. Esta a razão de empurrar uma simples reedição, que vai melhorada (para mim) pela capa de Ana Luísa [Escorel, designer, 
filha mais velha de Antonio Candido e Gilda de Mello e Souza]. Afetuoso abraço etc. (Apud Monteiro, 2018, p. 14, nota de rodapé).

Em 1946, Sérgio regressa a São Paulo, depois do quarto de século por ele denominado "interlúdio carioca”, para assumir ali a direção do Museu Paulista, dando início então à verdadeira intimidade entre ambos. Índios e mamelucos... aparece em 1949, na Revista do Museu Paulista, e é mais tarde incorporado como capítulo inicial de Caminhos e fronteiras (1957). A ideia deste último livro enseja em Candido a lembrança de uma sua iniciativa pela qual nutria "grande ufania": lamentando que "este e outros notáveis estudos de Sérgio ficassem pouco acessíveis, em publicações especializadas", sugeriu ao amigo Otávio Tarquínio de Sousa, amigo também de Sérgio, "que o estimulasse a compor com alguns deles um volume para a famosa Coleção Documentos Brasileiros” - inaugurada justamente por Sérgio Buarque em 1936, com a publicação de Raízes do Brasil, quando dela ainda à frente o Sr. Gilberto Freyre -, já dirigida por Otávio. Falou-se então com José Olympio, e o convite foi devidamente feito a Sérgio, que não houve por bem declinar. Essa é a história de como teria vindo ao mundo Caminhos e fronteiras, "que forma com Monções um par admirável dentro da orientação a que aludi, de estudos históricos vinculados pela cultura material e a ocupação do espaço” (Candido, 1983, p. 133).

\section{O conviver e a partilha}

A essa altura, Candido diz seguro, a amizade contraída estava mais do que consolidada, e a convivência seguiu constante até ser finalmente interrompida no ano da morte de Sérgio em abril de 1982. A esse respeito, Francisco de Assis Barbosa (1988, p. 35) é de pleno acordo: a despeito da diferença de idades, Antonio Candido se tornou, sim, grande amigo de Sérgio Buarque, "amigo dos maiores, e posso mesmo afirmar, dos prediletos dentre os da geração posterior à dos modernistas”. Para uma amostra do nível daquela amizade e conformidade intelectual, a quantas andavam, Candido menciona "noites e noites sem fim" nas quais, às expensas da hospitalidade de Maria Amélia - esposa de Sérgio -, debatiam “Gregório de Matos, os árcades, teoria literária, que naquele momento sofria influência do new criticism, de que ele se tornou grande conhecedor, inclusive reunindo uma biblioteca de crítica moderna, que depois me deu de presente" (1983, pp. 132-133). Não por acaso, Candido dedicará ao casal o seu livro Literatura e sociedade, em 1965, e Maria Amélia, por sua vez, há de confiar justamente a ele, ao cabo de 1988, isto é, mais de seis anos após a morte de Sérgio Buarque, os originais inéditos do marido concernentes àqueles temas, os quais Candido então reúne, estuda e organiza sob o título Capitulos de literatura 
colonial (1991). Sérgio, que em meados dos anos 1950 já havia tecido elogios a Antonio Candido - "um dos espíritos críticos mais atilados que o Brasil hoje possui" (1996, p. 196) -, há de lhe dedicar também o longo ensaio "Gosto arcádico", saído na Revista Brasiliense em 1956, mais tarde reformulado e compilado em Tentativas de mitologia (1979, pp. 241-271)3. Já em 1957, Candido informa prefacialmente ao leitor da primeira edição de Formação da literatura brasileira que este havia sido entregue à leitura de amigos, Sérgio Buarque de Holanda incluso, livro por todos bem recebido (1959, p. 10). O crítico revelará ainda uma pitoresca correspondência entabulada entre eles ao longo daquele decênio, cujos documentos ainda hoje, ao que consta, não foram dados ao trato, nem sequer a conhecer.

O caso foi que estando ele ensinando na Itália, onde ficou de 1952 a 1954, eu resolvi lhe escrever uma carta como se fosse de trezentos anos antes, mas dando notícia de coisas presentes. A linguagem era aquela tosca e irregular das Atas da Câmara, Autos de Visitação, etc. Havia problemas difíceis de resolver, como, por exemplo, dar uma notícia sobre Rodrigo Melo Franco de Andrade, nosso grande amigo, que era mineiro, mas Minas ainda não existia... Então inventei a fórmula: "natural de Cappitania das Minas que estam pera se achar". Anoto isso para contar a grande inventividade dele na resposta. Esta veio em mãos, trazida por um amigo comum que viajava de avião. De que maneira relatar este fato no século XVII? Sérgio escreveu: "He portador desta Dom Paulo Dalmeyda que se passa a esa Comquista na máquina Pasarola, que ha de inuentar a seo tempo o Padre Berto Lameu de Guzman da villa de Santos nessa marinha”. Daí se desenvolveu uma correspondência que, devo dizer, era bastante picante. Mas a certa altura eu não aguentei o tranco, porque estando em Nova York, creio que em 1966, ele me respondeu em inglês do século Xvir! De outra feita, quando estava no Chile, mandou em versos uma admirável Carta Chilena [1963], que Manuel Bandeira publicou, porque ele lhe mandou cópia (é a única divulgada). E mais tarde chegou a mandar uma em latim, desnorteando completamente a minha capacidade que parava no português de Piratininga seiscentista (Candido, 1983, p. 133).

Declarações como essas, em que avulta a figura estupenda do intelectual, são recorrentes nos escritos de Candido, dedicados às dúzias, vida afora, tanto à pessoa como à obra do amigo paulistano. Não à toa um Antonio Candido maduro - ainda, todavia, com a peremptoriedade própria dos arroubos da juventude -, pontuando, enfático, quase toda palavra da primeira oração seguinte, viesse a afirmar catego-

3. Nicodemo (2018, p. 113) informa 1957 como ano de publicação de "Gosto arcádico", que saiu, todavia, na Revista Brasiliense, n. 3, jan./fev. 1956, pp. 97-114. Sua versão aumentada, em Tentativas de mitologia, conteria as "únicas referências explícitas" que Sérgio Buarque fizera a Formação da literatura brasileira. 
ricamente: "O Sérgio Buarque de Holanda foi/ o/ homem/ mais/ culto/ que eu/ já/ vi/ na/ minha/ vida. Eu nunca vi um fenômeno igual” (2005). Não somente a magnificência de seu conhecimento, chamava atenção também a complexidade de Sérgio; o contraste excepcional entre a cultura portentosa de catedrático e a extroversão desinibida de malandro. Sérgio parecia o cúmulo do oximoro: "Ele era um erudito extraordinário e muito inclinado à molecagem. Ele era um camarada de uma seriedade intelectual fora do comum e um gozador de marca maior" ${ }^{4}$. Os depoimentos orais concorrem, portanto, àquele mesmo destino que ganha corpo e sentido em forma de letras. Expressivos como são, eles têm, no entanto, qualquer coisa de trivial no aspecto, quando ensaiam constituir a personalidade de outrem, no caso, um amigo íntimo.

“O homem é um feixe de contradições - eis um clichê de biógrafo", sentencia o historiador Peter Gay (1990, p. 135). Nada se afigura mais fácil, nada é mais comum, assevera, do que traçar pares de antíteses e, enfeixando-os paralelamente, dizer que compõem o retrato acabado do homem ${ }^{5}$. Velho ramerrão em narrações da vida e da morte, tão recorrente quanto a noção goethiana de que cada obra configura uma espécie de fragmento autoconfessional, a ideia da reflexão da personalidade na obra - obra que, por isso mesmo, pode ser "também vária e complexa”, como Candido observa a propósito de Raizes do Brasil (1988, p. 63) - denota que esta espelharia o seu autor simplesmente por ser o seu autor, indiferente a um sentido mais denso quanto à agência e ao esforço literários de sublimação das estruturas. Subsidiado ou não por tais premissas, foi Antonio Candido quem primeiro vislumbrou na estrutura de Raizes do Brasil sua construção "sobre uma admirável metodologia dos contrários" ([1967] 2016, p. 359), após lhe comentar determinado excerto; a impressão de seu uso da proposição fundamental dialético-real tomada de empréstimo da filosofia de Hegel - para quem, sabe-se, a contradição move o mundo, todas as coisas contradizem a si mesmas -, não desacompanhada dos conceitos de tipo da sociologia weberiana, emparelhados segundo uma fórmula algo esquemática (patrimonialismo-burocracia, caudilhismo-liberalismo etc.), porém camuflada pela elegância estilística a envolver, fluente e concisa, uma descrição crítico-sociológica original da sociedade brasileira, consubstanciada nesse primeiro ensaio de Sérgio Buarque.

4. Depoimento oral de Antonio Candido no documentário Raízes do Brasil (Santos, 2004). Há nesse seu comentário uma aparente remissão ao conceito de "equilíbrio de antagonismos" manejado por Gilberto Freyre, que tomara de empréstimo, por sua vez, aos autores ingleses novecentistas - que o finado crítico, aliás, não desconhecia.

5. A propósito, contudo, de um perfil traçado de Oswald Andrade, Antonio Candido concordava ser "banal dizer de alguém que é dividido, porque no fundo todos somos. Mas há divisão e divisão” (1993, p. 35). 
Ainda hoje não parece demais pontificar: é devida sobretudo a Antonio Candido a franca recepção de Raízes do Brasil. Ou, como queiram porventura, de um seu viés. Deve-se a esse intelectual mineiro, radicado em São Paulo, a preeminência da vertente a partir da qual se amontoou positivamente a fortuna crítica do clássico de Sérgio Buarque, se contada da segunda metade da década de 1960 em diante. Seu prefácio de 1969, intitulado “O significado de Raizes do Brasil”, assumiu com o tempo, e talvez inadvertidamente, uma função propedêutica tal qual a da clave em uma partitura; nele, Candido parece ter atuado como um tipo de souffeur - o "ponto", como se designa tal profissional em português, utilizando-se aqui terminologia artística -, aquele que, dos bastidores, sopra ao ator no estrado as falas de seu próprio roteiro. Logo, arrisca-se dizer mais: Antonio Candido foi decisivo para a sagração do livro - e, decerto, a de seu autor - como clássico entre as "formas gigantes" ("Giantforms to the public”, na expressão poética de William Blake) da literatura nacional não ficcional.

O esforço de Antonio Candido em dissociá-lo de qualquer vinculação ao autoritarismo, dado o pouco apreço original de Sérgio Buarque pelo ideário liberal-democrático (Waizbort, 2016 e 2011; Johnson, 1995, pp. 168-172; Ribeiro, 2018) - sentimento de suspeita típico do período entreguerras -, não parece ter sido menor do que o do próprio Sérgio. Alguns artigos seus, cujos títulos são bastante sugestivos, dão conta dessa cumplicidade e tentativa: "Sérgio em Berlim e depois", "Sérgio, o radical" "Radicalismos" "A visão política de Sérgio Buarque de Holanda" "Minha amizade com Sérgio", entre outros. E ambos tiveram êxito nisso, como hoje se deve reconhecer, conquanto Sérgio Buarque tenha definitivamente se valido, para tanto, menos do contributo retrospectivo de um Espírito do tempo, e mais de uma trama de automistificação metodicamente entrelaçada a muitas mãos, cônscias disso ou não.

Há, todavia, circunstâncias de sua vida ainda hoje pouco ou nada exploradas, embora possivelmente esclarecedoras. O que se sabe, por exemplo, dos seus anos de graduação, levada a cabo no Rio de Janeiro do primeiro meado do século anterior? O que se preservou de seus dias "involuntariamente" despendidos nas salas de aula da Faculdade Nacional de Direito? O que se conhece a seu respeito quanto à dúzia e meia de meses vividos como correspondente na Alemanha, quando dos estertores da República de Weimar? O que há de registrado desde o seu retorno, meio forçado pela vitória da Revolução de 1930, até constranger-se à revisão, em 1948, de seu primeiro livro, para si crescentemente incômodo? Depreende-se de sua fortuna biográfica "relativamente pouco", muito pouco, é o que conclui o historiador Sérgio da Mata (2016, p. 73). Teriam os livros de Weber e as lições de Meinecke, "como reza o velho topos dos estudos sergianos, e como afirmou o próprio Sérgio", indicando-lhe "novos 
caminhos", deixado marcas em sua Teoria da América, de cujos esboços teria advindo Raízes do Brasil mais tarde? "Não se trataria, antes, de uma tentativa de mitologia?", indaga-se da Mata (2016, p. 73).

No que tange a Friedrich Meinecke, o historiador mineiro coloca em dúvida as lições dele tomadas. Após pesquisar na Staatsbibliothek zu Berlin os Vorlesungsverzeichnisse de 1929-1931, isto é, o compilado de cursos universitários semestralmente oferecidos durante o período em que Sérgio esteve na capital da Alemanha, o que descobriu não o deixou convencido de que "Herr Hollander", longe da condição de aluno regular da então chamada Friedrich-Wilhelms-Universität, tenha tido acesso, não obstante, a qualquer uma das sessões dos quatro cursos ministrados por Meinecke no período. Nada impede que ele possa ter assistido a uma ou outra conferência naqueles dias, condescende. Porém, "frequentar preleções ou seminários do grande historiador das ideias, ainda que 'sem regularidade', parece ser praticamente impossível” (Mata, 2016, p. 74). Corrobora sua descrença o fato de que, em 1936, "Meinecke publicava então seu último grande livro, O surgimento do historicismo" (2016, p. 73), justamente no ano em que vinha a lume Raizes do Brasil, o exato oposto, em sua construção e concepção, da historiografia historicista de que Meinecke foi, talvez, o último grande representante e defensor, ainda segundo da Mata. Em sua busca da "Alemanha secreta" - uma alusão irônica à expressão geheimes Deutschland, cunhada pelo poeta Stefan George - em Raizes do Brasil, livro “meio alemão" de que fala Antonio Candido, Sérgio da Mata suspeita que a única obra de Meinecke que Sérgio Buarque parece ter lido, anteriormente à publicação de seu primeiro ensaio, foi porventura Weltbürgertum und Nationalstaat, de 1908, a qual se encontra em sua vasta biblioteca conservada pela Unicamp e que conteria apenas um único trecho grifado, "algo bastante incomum", se se considerar o intenso manuseio da maioria de seus livros.

Já quanto a Max Weber, Sérgio Buarque se gabava - um tanto como Freyre, nos idos da década de 1920, em relação a James Joyce - de ter sido o primeiro brasileiro a citá-lo em um trabalho qualquer. Aos olhos de Sérgio da Mata se torna, entretanto, "cada vez mais difícil, hoje, subscrever leituras como as de Brasil Pinheiro Machado [...] e Pedro Meira Monteiro [...], que apostavam no weberianismo do livro", pois, ainda na sua opinião, "quem quer que esteja atento aos fundamentos intelectuais e filosóficos da obra de Weber sabe que ele sempre se situou no polo oposto da Lebensphilosophie e de todo irracionalismo" (2016, p. 64), cujos componentes restaram demonstrados menos ou mais abertamente por João Kennedy Eugênio (2011) e Leopoldo Waizbort (2011), em contraposição à tradicional exegese progressista que tem no crítico Antonio Candido o seu primeiro ou mais alto prócer. A este, a bem da verdade, não passou despercebido o caráter dito arbitrário e perigoso desse contexto e atmosfera históricos, dos quais o moço Sérgio respirou os ares, 
sem no entanto ignorar o que de pernicioso havia naquele ambiente - "a duvidosa caracteriologia de Ludwig Klages", "o caldo cultural que podia ir de conservador a reacionário, de místico a apocalíptico”. Face a tudo isso, Sérgio incrivelmente não soçobra, passará incólume: “a retidão de seu espírito, a jovem cultura já sólida e os instintos políticos corretamente orientados" hão de levá-lo a um produto surpreendente - porque "despojado por ele de qualquer traço de irracionalidade" -, para o qual tirou elementos com vistas a "uma fórmula pessoal de interpretação progressista do seu país, combinando de maneira exemplar a interpretação desmistificadora do passado com o senso democrático do presente" (Candido, 1982, pp. 7-8). Sérgio não se deixara contaminar, portanto, por quaisquer tendências de "renovação reacionária do idealismo objetivo", sobretudo a "filosofia da vida" e a "psicologia realista" de Dilthey, elencadas por Lukács (2018, p. 48) entre as mais adequadas à satisfação das necessidades ideológicas da burguesia imperialista alemã, ao cabo do século XIX, do que propriamente o neokantismo liberal. Quem pode sobressair assim o faz porque dotado de "uma consciência democrática, como era e sempre foi" o seu caso. São estas impressões de Antonio Candido, tenha-se sempre em mente.

A historiadora Emília Viotti parece participar, em todo caso, desse entendimento precursor, quando, ao discorrer sobre "a grandeza de Sérgio", aponta que ela residiria "sobretudo no sentido democrático, que o leva a antecipar a entrada do povo na história” (Costa, 2015, p. 221). "A reação de Sérgio contra esse ponto de vista conservador, que induzia o observador à passividade", ora no escrutínio de Leandro Konder - filósofo marxista também alinhado, ao que consta adiante, àquela concepção -, "consistiu em reexaminar de um ângulo energicamente crítico o panorama da nossa história, para enxergar as manifestações de movimentos subterrâneos em áreas culturais nas quais se negava a existência de qualquer movimento significativo" (1991, p. 63). Sérgio lhes parecia, enfim, ter naturalmente assumido as "boas posições políticas", sem jamais vacilar se instado a defrontar-se com as consequências de suas tomadas de decisão. Tanto que chegou a ser detido em 1932, dizem, encontrando-se no Rio, por se postar decididamente, bom paulistano que era, ao lado da Revolução Constitucionalista contra o governo de exceção (Candido, 1982, p. 9; 1998, pp. 8189). O próprio Sérgio, certa feita, narrara o imbróglio à esposa, provendo-o até com mais detalhes, à guisa de depoimento policial: que estando no Rio de Janeiro, "na turma dos boatos e da torcida revolucionária", acabou preso, "soltando vivas a São Paulo, em pleno Mangue"; que "no meio de um grupo de onde constavam Otávio Tarquínio de Sousa, Tristão da Cunha, Ribeiro Couto”, todos comboiavam “o escritor francês Luc Durtain" (Holanda, M. A., [1979] 2006, p. 433).

O episódio causa espécie, mesmo assim reduzido a poucas linhas, menos por uma sua eventual repercussão do que pelo seu desconcertante anacronismo. Pois, 
a se julgarem verdadeiras as teses de que Raízes do Brasil seria "fruto de uma insatisfação que gerou a revolução [de 1930] e não vice-versa” (Matos, 2006, p. 153; Matos, 2008; Feldman, 2016, pp. 197-254), de que o seu autor, se não cooptado, fora atraído pelo seu "aspecto falsamente revolucionário" (Leite, 2002, pp. 380-381), como explicar, então, que, anos antes, o jovem intelectual se deixasse aprisionar em cárcere, na condição paradoxal de apoiador do próprio regime? O empreendimento de uma busca exaustiva por notícias veiculadas nos periódicos cariocas da época, compreendidas no interstício em que se desdobraram os conflitos da Guerra Paulista, não recompensou o esforço despendido com nenhum achado passível de confirmar o relato da prisão de Sérgio Buarque de Holanda, devida a motivações políticas. A pesquisa veio a se dar, no entanto, com um recorte no mínimo curioso, publicado no Jornal do Brasil, edição do dia 14 de agosto de 1934, intitulado "Conflito num bar: muita pancadaria e três pessoas feridas, uma das quais gravemente”. Preservadas a grafia da época e a pontuação original, a cena abaixo é, por sinal, algo aparentada àquela que as memórias de Sérgio puderam então ditar à esposa - um grupo carioca, uma ocasião entusiasmada, a pessoa de um estrangeiro:

O bar do arraial, á rua do Lavradio n. 202, teve no começo da madrugada de ontem momentos de grande agitação.

Após já ter estado em outros estabelecimentos, um grupo de rapazes que comemorava uma data íntima, ali foi ter. Sentaram-se os recem-chegados a uma mesa e pediram lhes fossem servidas bebidas.

A princípio o Sr. Manuel Rocha, co-proprietario do bar, relutou em atende-los prevendo acontecimentos desagradáveis, mas finalmente acedeu e as bebidas foram trazidas pelos garçons para a mesa dos alegres freguezes.

Momentos depois, conforme iam esvasiando as garrafas, os animos dos componentes do grupo iam tambem se exaltando e o Sr. Rocha, receioso, depois de chama-los á ordem varias vezes sem ser atendido, pediu o auxilio da polícia do $12^{\circ}$ distrito, que mandou ao local o soldado n. 138 da $4^{\mathrm{a}}$ companhia do $1^{\circ}$ batalhão.

Este ao chegar ao local foi logo agredido pelo grupo e chamou em seu auxilio o colega n. 116 da mesma companhia e batalhão e o guarda civil n. 609.

Dispostos a resistir á ação policial, os rapazes enfrentaram os dous soldados, o guarda civil e ainda o $2^{\circ}$ Tenente da $2^{\mathrm{a}}$ linha do Exército Napoleão Fernandes de Souza, estabelecendo-se formidável conflito que só cessou com a intervenção do comissário Virgílio e outros policiais. Serenados os animos verificou-se que um dos brigões, o jovem Brydon Taves, norte americano, empregado da United Press estava com o craneo fraturado em consequencia de violenta quéda, o Tenente Napoleão tinha o olho direito contundido e o soldado n. 116 recebera também algumas contusões. 
Os outros companheiros de Brydon, que eram o jornalista Amadeu Amaral Filho, morador á rua Candido Mendes n. 57; José Pontes de Moraes, residente na mesma casa e o advogado Sérgio Buarque de Hollanda, domiciliado á rua Maria Angélica n. 39 foram autoados na delegacia do $12^{\circ}$ distrito, pelo delegado Jayme Praça, tendo prestado as respectivas fianças. Brydon, depois de socorrido no Posto Central de Assistencia, foi removido para o Hospital dos Estrangeiros ${ }^{6}$.

No dia 12 de outubro de 1935, a seção “O Direito e o Fôro” de O Jornal - para o qual, durante o biênio 1929-1930, Sérgio enviava reportagens como correspondente em Berlim, a convite de um dos donos, o futuro magnata das comunicações Assis Chateaubriand -, que não dera notícia de sua prisão no ano anterior, divulgará, nada obstante, a absolvição do trio, por sentença do então juiz da primeira vara criminal do Rio de Janeiro, “dr. Nelson Hungria”, que chegaria, dali a menos de duas décadas, a ministro do Supremo Tribunal Federal. Sérgio Buarque talvez não contasse com a mesma "sorte", caso a ação penal em que figurou como réu não houvesse sido distribuída àquele magistrado, futuro "príncipe dos penalistas brasileiros". Pois logo abaixo da notícia de sua absolvição, consta extrato semelhante de uma decisão desta vez de lavra do juiz da segunda vara criminal, mediante a qual "foi condemnado" um certo "Benedicto Corrêa de Souza a dois meses de prisão, porque no dia 17 de julho de 1935 [ou seja, menos de três meses antes], entrou no botequim da Praça Serzedello Correia n. 27 e promoveu desordem, e preso resistiu à prisão”.

Reitere-se que não recai sobre Antonio Candido a autoria da história sobre o “crime de lesa-majestade" eventualmente cometido por Sérgio Buarque em 1932 - é partícipe apenas da divulgação do suposto ilícito heroico (e não apenas Candido: vide, por exemplo, Monteiro, 2012, p. 415). A ele se deveriam, antes, outras "invenciones" a respeito do amigo, como Wanderley Guilherme dos Santos o adivinha ${ }^{7}$. Pedro Monteiro e Lilia Schwarcz (2016, pp. 20-21) também insinuaram algo nesse sentido, ao compará-lo ao controverso personagem homônimo do conto "Pierre Menard, autor del Quijote", de Jorge Luis Borges, publicado em 1939, no qual sobressai uma metafísica da criação e reprodução do fenômeno literário. Isso posto, à guisa de Borges, poder-se-ia atribuir a Antonio Candido a autoria de Raizes do Brasil, conforme a pergunta retórica de João Kennedy Eugênio? (2011, pp. 395-399). Valendo-se de um autor alemão, Müller-Freienfells, o próprio Antonio Candido

6. Notícia não assinada e intitulada "Conflito num bar: muita pancadaria e três pessoas feridas, uma das quais gravemente”. Jornal do Brasil, 14 de agosto de 1934, seção Na Polícia e nas Ruas, p. 13.

7. "Sérgio Buarque de Holanda? O do livro Raizes do Brasil é uma invenção do Antonio Candido. O Sérgio da História geral da civilização brasileira é muito bom, mas não é esse que se vende por aí." (Apud Gaspari, 1994, p. 42). 
advogava que, mesmo considerando-se "a priori metafísico o valor artístico, só de modo sociológico é possível elucidá-lo nas suas formas concretas particulares - pois nas sociedades civilizadas a criação é eminentemente relação entre grupos criadores e grupos receptores de vários tipos" (2006, p. 82). Em prefácio à quarta edição de Raizes do Brasil, Candido aludia ao devir do livro durante o "período mais transformador dos estudos sociais no Brasil”, o qual teria sido atravessado pelo livro com certo desembaraço até finalmente despontar como o clássico que então se tornou; e introduzia, logo em seguida, as ditas razões de uma tal destreza e incolumidade ([1963] 2016, pp. 351-353).É também de Antonio Candido - cuja clarividência se tornou de instantâneo parte integrante e há muito indissociável da obra na forma de um segundo prefácio, o aludido "O significado de Raizes do Brasil", que nela passou a constar desde a quinta e última edição revisada - a autoria do sintagma "clássico de nascença” ([1967] 2016, p. 356), o qual, nos últimos tempos, tem dado o que falar em meio àqueles que se devotam a uma ou outra produção ensaística da década de 1930 em especial.

Raizes do Brasil nasceu mesmo um clássico? A expressão "clássico de nascença" parece sugerir que o seu reconhecimento por um grande público - ou, quando menos, por um público experimentado - se dera algo autônoma e imediatamente. O historiador Ronaldo Vainfas (2010, p. 556) refuta um seu possível acolhimento nesse sentido, ao mais tarde constatar que o livro, a bem da verdade, esperaria anos para alçar voo: "A segunda edição (ampliada e muito modificada) de Raizes saiu em 1948 pela José Olympio, doze anos após a publicação original”; as reedições subsequentes, relembra, foram igualmente "lentas $(1956,1962)$ e só deslancharam depois da quinta edição (1969), ano em que Sérgio Buarque se aposentou da USP”. Em uma significativa nota de rodapé, Vainfas ainda cuidou de cotejar o seu desempenho a nível editorial face a Casa-grande \& senzala: bastante “modesto", deduz em desfavor do primeiro. As primícias de Gilberto Freyre ${ }^{8}$ logo conheceram reedição três anos depois de seu lançamento. Ao mesmo passo em que Raizes do Brasil alcançava sua quinta e última edição revisada, há quase exatos cinquenta anos, Casa-grande \& senzala atingia já a marca considerável de catorze edições.

Quanto a traduções, Raizes recebeu versões em italiano (1954), espanhol (México, 1955), japonês (1971), enquanto o autor era vivo, e mais três póstumas: chinês (1995), alemão (1995) e francês (1995) [e inglês (2012)]. Casa-grande \& senzala, por sua vez, recebeu inúmeras

8. Saídas em 1933 pela Livraria Schmidt Editora e que passarão, mais tarde, a ser reimpressas pela editora José Olympio, a mesma por que surgiu Raizes do Brasil, cabeça de coleção impressa sob os auspícios do próprio Freyre. 
traduções desde 1942: espanhol, inglês, francês, alemão, italiano, polonês, húngaro, romeno, japonês. Em 1971 havia já nove traduções do livro (Vainfas, 2010, p. 556).

Casa-grande \& senzala é que teria sido, na linguagem corrente, um verdadeiro livro arrasa-quarteirão logo de partida. De tal modo que, em um tratado sobre a história dos impressos no país, o brasilianista Lawrence Hallewell (2017, p. 489) houve por bem situar Gilberto Freyre entre os literatos mais bem-sucedidos na década de 1930, ao lado de Jorge Amado, Rachel de Queiroz, Graciliano Ramos e Vinícius de Moraes, para citar aqui apenas os escritores de maior vulto e relevo aos olhos hodiernos. O próprio Antonio Candido ([1967] 2016, p. 356) chegou a externar que o jovem leitor talvez não mais fosse capaz de adivinhar "a força revolucionária, o impacto transformador" que Casa-grande \& senzala, "este grande livro", produziu de imediato sobre a juventude intelectual a eclodir no primeiro meado daquela década politicamente efervescente. $\mathrm{O}$ assim conciso, curto, discreto Raizes do Brasil repercutiria bem menos na imaginação dessa mesma mocidade. De sorte que o exercício comparativo de Vainfas, trazido a efeito com vistas à demonstração da recepção crítica de ambos os volumes no decorrer dos últimos oitenta anos, o leva, pois, a concluir - com algo de cabal no tom: "o fato é que a obra de Sérgio Buarque de Holanda, incluído o Raizes do Brasil, custou a ser incorporada pela pesquisa histórica brasileira" (Vainfas, 2010, p. 556; Nicodemo, 2016, p. 160).

Daí surpreender a asserção de Laura de Mello e Souza, em prefácio ao segundo livro de Sérgio Buarque, Monçôes (1945), o qual teria surgido no desvio do rastro do "grande sucesso" obtido pela sua obra anterior (2014, p. 19). Ora, Laura mesma figurou entre os já célebres entrevistadores reunidos em meados de 1981, no Museu da Imagem e do Som, por ocasião do depoimento de Sérgio Buarque na série idealizada por Boris Kossoy, então diretor do MIs. Ali ouviu dele próprio, portanto, que o seu primeiro livro não teve lá esse sucesso todo: "custou muito a ter uma reedição, que só veio em 1947 [ou seja, dois anos após a publicação de Monçôes]" ([1981] 2004, p. 6)9 . Sérgio Buarque dizia ter a impressão de que foi, antes, o prefácio escrito pelo pai de Laura de Mello e Souza, Antonio Candido, que "deu sorte" a Raizes do Brasil, pois a partir daí “o livro passou a ter muita reimpressão, às vezes duas por ano." ([1981] 2004, p. 6).

Se é certo que um autor tem consciência plena de sua obra tão somente quando esta se lhe é arrostada por meio da reação do público - condição por excelência para que conheça "a si próprio, pois esta revelação da obra é a sua revelação" (Candido,

9. A propósito de Monções, o sintagma "clássico de nascença", Candido acabou por fazer escola entre os seus. Afinal, com a mesma locução - embora com uma leve variação - Laura de Mello e Souza também qualificará o referido livro (2014, p. 36). 
2006, p. 84) -, a crítica lograda por Raizes do Brasil ao tempo em que trazido ao público de 1936 manifestará um Sérgio Buarque de Holanda essencialmente diverso do democrata radical desenhado pelo amigo n'“ $\mathrm{O}$ significado de Raizes do Brasil", de 1969. Dá-se uma amostra: em uma longa recensão publicada no dia 7 de novembro de 1936, na seção "Registro Literário" do Jornal do Brasil, assinada pelo já imortal à época Múcio Carneiro Leão (1936, p. 8; Eugênio, 2016, p. 431), este aduz que "seria dificílimo" identificar com precisão a posição política assumida pelo autor de Raizes do Brasil.

[...] Seu pensamento, em tal campo, me parece cheio de contradições. Em uma das páginas do livro, faz ele observar que o brasileiro tem a tendência a aceitar as ideias mais díspares, associando, em seu espírito, convicções e preceitos que, no espírito de qualquer outro povo, serão os inimigos mais ferrenhos. Parece-me que o Sr. Sérgio Buarque de Holanda incorre um pouco em sua própria observação. Assim é que o vemos, num trabalho que aparece em apêndice no livro, combater vivamente o integralismo, a propósito do Sr. Otávio de Faria. E, entretanto, na página 158 do volume o vemos sustentar sem nenhum propósito possível de paradoxo, a vantagem das tiranias. Ouçamo-lo: "É claro que um amor humano que se asfixia e morre fora do seu circuito restrito, não pode servir de cimento a nenhuma organização humana concebida em escala mais ampla. Com a cordialidade, a bondade, não se criam os bons princípios. É necessário um elemento normativo, sólido, inato na alma do povo ou implantado pela tirania para que possa haver cristalização social. A tese de que os expedientes tirânicos nada realizam de duradouro é apenas uma das muitas invenções fraudulentas da mitologia liberal, que a história está longe de confirmar”.

Aí está uma maneira de falar clara e sem rebuços. Será isso o modo de pensar de um republicano? de um liberal-democrata? Ou será, antes, a maneira de doutrinar de um discípulo de Hitler? [...]

Em que pese a noção, sustentada por Candido, de que Raízes do Brasil teria o condão de constituir um programa ideológico potencialmente apto a dar corpo a uma política efetivamente popular, o cronista Jayme de Barros não estaria com ela de acordo, uma vez que o surpreendeu, em resenha no Diário da Noite de 23 de novembro de 1936, a flagrante indefinição do livro, no qual "faltam sempre as soluções” de qualquer cunho. Ao sentir que Sérgio Buarque "parece insinuar apenas o erro econômico da Abolição da escravatura, sem um preparo seguro" (1936, p. 2), Barros lhe apõe a seguinte contestação: “Ora, problemas dessa ordem nunca foram resolvidos racionalmente. Nos Estados Unidos a libertação dos escravos custou uma guerra, que nem por isso custou o seu crescimento harmônico". Meses depois, na mesma seção e diário, Barros lamentará a falta de uma "segura orientação 
sociológica", via de regra, tanto aos antigos como aos novos pesquisadores voltados ao estudo do passado nacional e à decifração de seu futuro - figurando entre eles o Sr. Sérgio Buarque de Holanda -, os quais seguem mantendo certo círculo vicioso: os novos, após herdarem "a vasta documentação" que lhes deixaram os antecessores, continuam ainda "a expor, a indagar, a divulgar, sem descobrir conclusões precisas e claras." (1937, p. 2).

Por sua vez, o pernambucano radicado em Minas, Oscar Mendes (1937) - espécie de Alceu Amoroso Lima do rodapé literário nas Gerais -, ressaltava a impressão de problema insolúvel com que deixava a leitura de Raizes do Brasil; resgatando algumas das páginas do livro resenhado, Sérgio Buarque lhe parecia um daqueles tipos que criticava em seu próprio ensaio.

\footnotetext{
Não diz o que quer e o que acha conveniente e aconselhável, obrigando a gente a formular uma grande interrogação. Será o sr. Sérgio Buarque um daqueles intelectuais "que se alimentam, ao mesmo tempo, de doutrinas dos mais variados matizes", sustentando, "simultaneamente, as convicções mais díspares"? Ou terá alguma "raiz" mais vigorosa para suster a árvore, ou pretende revigorá-la, infundindo seiva nova, com “um galho" estrangeiro, prudente ou violentamente enxertado?
}

O crítico Oscar Mendes cita, nesse excerto, trechos de Holanda, [1936] 2016, p. 273. Logo, ao que aparenta, Sérgio Buarque não fora um extemporâneo no sentido nietzschiano, mas justamente um legítimo filho do seu tempo, a cujos contemporâneos Raizes do Brasil teria fornecido "indicações importantes para compreender o sentido de certas posições políticas daquele momento, dominado pela descrença no liberalismo tradicional", a que Antonio Candido fez menção ([1967] 2016, p. 356). Ora, Sérgio era ele próprio um desses jovens incrédulos face às "invenções fraudulentas da mitologia liberal”, como sentencia na primeira edição de seu ensaio (Holanda, [1936] 2016, p. 327). Ao prefaciá-lo, Candido parecia desconhecer que a primeira edição de Raizes do Brasil veio a ser varrida "de passagens ou expressões que pudessem causar desconforto nos leitores mais simpáticos a uma visão liberal e democrática da política”. Por esse motivo, supõem ambos os organizadores da edição crítica de Raizes do Brasil, saída apenas em 2016 pela Companhia das Letras, que o prefácio de Antonio Candido talvez tenha contribuído para a estabilização da obra, "como se ela tivesse 'nascido' assim: pronta para o pensamento democrático e liberal" (Monteiro e Schwarcz, 2016, pp. 13 e 17).

Assinalou-se, inclusive, que o referido prefácio se converteu em uma espécie de "entidade paralela" à de Raizes do Brasil, ao ponto de ganhar tanto ou mais visibilidade e destaque que o livro em si (Gontijo e Franzini, 2009, p. 157), o que, de certo modo, 
reforça uma opinião do próprio Candido, segundo a qual subsistiria uma estranha mania brasileira pelas coisas "sumárias e indicativas" ([1962] 2000, p. 15) ${ }^{10}$. Não ocorreu a Antonio Candido, todavia, que Raizes do Brasil adquirisse, no decurso de mais de trinta anos e cinco revisões ao todo, verdadeira natureza acomodatícia, fruto do gestual palinódico de seu autor, a que Luiz Feldman (2016), com a deferência peculiar a seu ofício diplomático, prefere chamar "amadurecimento".

Guardadas as proporções devidas, Goethe é uma amostra aproximada de tal amadurecimento, ao se ter notícia de que, em 1849, o centenário de seu nascimento passou quase despercebido em sua terra natal. Para então emergir e se ver alçado ao posto solene de representante nacional das letras alemãs ao fim do século XIX - não à toa em meio à consolidação do Estado-nação prussiano -, a personalidade e a obra de Goethe (ambas muito pouco ortodoxas, diga-se de passagem) tiveram de sofrer uma releitura significativa. De modo análogo, o historiador André Carlos Furtado (2014, pp. 73-75; no mesmo sentido, Carvalho, 2015, pp. 112-113) logrou demonstrar, a partir da recuperação de um sem-número de depoimentos e discursos de amigos ilustres e demais admiradores, veiculados na imprensa ao fim de abril de 1982, que a imagem de Sérgio Buarque de Holanda, à qual se renderam homenagens por ocasião de sua morte, não era senão a imagem de expoente democrático tal como debuxada por Candido - este, na ocasião, já havia muito um intelectual de nomeada - no prefácio constante na quinta e última edição de Raizes do Brasil, lançada em 1969, quando do apogeu da repressão perpetrada pelo regime militar de 1964.

Para fazer dele um clássico propriamente dito, talvez Raizes do Brasil tenha sentido, pois, a necessidade que Sainte-Beuve vislumbrou no modelo de Homero, a propósito da natureza dos livros clássicos: de se lhe atribuir " a posteriori um desígnio, um plano, intenções literárias, qualidades [...] que seguramente nunca lhe ocorreram, entregue que estava ao desenvolvimento abundante das suas inspirações naturais". Contemplar o fim de tantos outros livros, sem dúvida igualmente dignos de sobreviver, mas que sucumbiram para sempre debaixo da areia das épocas, é o bastante, segundo o mesmo crítico francês, para que o espírito honesto venha a se dar conta de que essa ordenação canônica, prevalente desde então, "foi, na verdade", artificial e seletivamente "introduzida nas nossas admirações do passado" ([1850] 2013, p. 350).

André Furtado por óbvio não credita a Antonio Candido o êxito exclusivo de conferir a Sérgio uma "outra entrada", ao largo das muitas manifestações e leituras que "auxiliaram na concepção e formação do cânone”. No entanto, é plausível ad-

10. Comprovaria ainda a tese de que prefácios e comentários elogiosos são por vezes aptos a transferir a outrem, ainda que parcialmente, o capital do autor consagrado que o subscreve, observando-se também nisso relações de estratégia, interesses etc. (Bourdieu, 2004, p. 170). 
mitir que a influência sobre as possíveis direções ulteriores que uma obra venha a assumir não deriva de um único agente trivial, por exemplo, o leitor comum, o qual conforma uma "abstração que só pode concretizar-se como sombra, pela via indireta e enganadora das tiragens, das vendas e dos documentos relativos à distribuição e ao consumo", na concepção de Leyla Perrone-Moisés (1998, p. 13). Nessa arena literária em que os grupos não dispõem de isonomia no tocante aos níveis de poder, influência e autoridade para definir a realidade de um determinado livro - no caso, Raizes do Brasil -, isto é, não detêm "propriedade”, no sentido de Joseph R. Gusfield (1981, p. 10), esta propriedade não se deve, portanto, a "leituras anônimas e tácitas", providas de "efeito inverificável e uma influência duvidosa" (Perrone-Moisés, 1998, p. 13), mas precisamente à intrínseca "leitura ativa" de um então proeminente crítico literário - Antonio Candido, claro -, que se deparou "essencial para a (re) apresentação” de Sérgio Buarque nos anos 1980, em um panorama social de lenta, gradual, mas nada segura abertura política (Furtado, 2014, p. 75). Só ultimamente a propriedade de Candido e seu domínio do problema Raizes do Brasil ${ }^{11}$, por assim dizer, o poder simbólico com que dispõe sobre ele, vêm sendo reivindicados por um público constituído pelo livro ressurgido, compreendendo entidades e intelectuais mais ou menos devotados ao estudo do pensamento social brasileiro, como expressão em parte aproximada do que o crítico britânico Frank Kermode denominava controle institucional de interpretação (1979, pp. 72-86).

Logo, à questão suscitada quanto à possibilidade de se atribuir a Antonio Candido, um tanto hiperbolicamente, a autoria de Raizes do Brasil, João Kennedy Eugênio responde que lhe imputar tal condição seria de todo indevido, "se por invenção se quer sugerir que se trata de leitura infundada”, pois a leitura sociológica do ensaio o precede e foi empreendida, aliás, pelo próprio autor, da qual decorreram as revisões experimentadas sobretudo em 1948 e 1956, ano da segunda e terceira edições, respectivamente. Ou seja, "a leitura sociológica e progressista não é invenção de Antonio Candido" - é sua apenas a ênfase enviesada no radicalismo intempestivo do livro -, mas, sim, de Sérgio Buarque em pessoa. Eugênio então inverte o complemento: "Candido (enquanto leitor de Raizes do Brasil) é que é uma invenção de Sérgio Buarque" (2011, p. 399). Como se Candido personificasse, a título de ilustração, o crítico de arte de certa história futurista, que viaja de volta no tempo para conhecer as obras de um pintor nova-iorquino pelo qual é fascinado, mas lá chega a descobrir que "o pintor é um bêbado inútil, que rouba dele a máquina do tempo e foge para o

11. Em várias ocasiões, João Cezar de Castro Rocha afirma que Raizes do Brasil constitui um "livro-problema” com o qual os estudos históricos, literários e sociológicos devem cada vez mais e atentamente se ocupar (2004, p. 115; 2012a, p. 16; e 2012b, p. 26). 
futuro"; vendo-se preso àquele tempo que não é o seu, o crítico passa então a pintar "todos os quadros que tanto o fascinaram no futuro e o fizeram viajar para o passado" (Žižek, 2012, p. 44).

No entanto, estando-se a par de tal interação, a reciprocidade assoma um tanto mais complexa e intrincada do que Eugênio parece sugerir, pois Sérgio Buarque se encontrou, a determinada altura, plenamente identificado com a imagem que Candido fizera dele retrospectivamente, o que se depreende da seguinte declaração na aludida entrevista concedida a Laura de Mello e Souza:

O fato é que o livro [Raizes do Brasil] foi concebido de uma maneira, e se fosse conceber outra teria que fazer um livro inteiramente novo. Mas acredito que ele ainda tem valor: o livro foi publicado em 1936, uma época muito dura para o Brasil, quase tão dura quanto a atual. E nele afirmo que uma revolução no Brasil não pode ser uma revolução de superfície: teria de ser uma revolução que levasse em conta todos os elementos mais aptos que estão por baixo. Essa é uma afirmação que já na época era difícil fazer. (Holanda, [1981] 2004, p. 10).

Ao mesmo passo em que a ponderação acima põe em xeque certa alegação de Antonio Candido, algo lastimosa - "Sérgio não me lia” (apud Nicodemo, 2018, p. 107) -, ela parece confirmar e até mesmo radicalizar a reiterada suposição de Leopoldo Waizbort (2007, pp. 90-112; 2002, p. 182) quanto ao "diálogo entre Sérgio Buarque e o autor da Formação". Retomando, portanto, o léxico artístico utilizado no início do artigo, Antonio Candido funcionou como um tipo de souffleur precisamente porque o texto de Raizes do Brasil, já então muitas vezes revisado por Sérgio Buarque, chegou-lhe às mãos, afinal, como uma espécie de didascália. Nesse aspecto, Antonio Candido talvez não fosse, afinal, um Pierre Menard, mas, antes, um Kafka no sentido de Jorge Luís Borges: um tipo de escritor que concebe retrospectivamente os próprios precursores (Candido, [1943] 2002, p. 120).

Que o prestígio conquistado por Sérgio Buarque tenha se dado unicamente às custas de Antonio Candido ou, quando menos, do prefácio por este escrito a Raizes do Brasil em 1969, eis um asserto tão exagerado quanto inverossímil. Para refutá-lo, talvez bastasse apenas mencionar que bem antes, em 1958, ano do concurso de Sérgio para a cátedra de História de Civilização Brasileira da Usp, outro Antonio - Soares Amora - lamentava, inconformado, que se tivesse de "exigir de homens da estatura intelectual e do saber de Sérgio Buarque de Holanda” a ordinária submissão “a um concurso de provas". A queixa de Soares Amora, de quem Sérgio seria colega mais tarde na Academia Paulista de Letras, consta expressamente no Processo Rusp n. 757/58, mediante o qual o candidato - já ilustre, pelo visto - protocolara sua inscrição no certame (Sanches, 2011, pp. 243-244). 
À guisa de conclusão, tomando-se como verídica a história contada por Pedro Meira Monteiro - não há razões fundadas para infirmá-la - acerca de sua última visita a Antonio Candido, quando ele e Lilia M. Schwarcz foram ao seu apartamento a fim de lhe trazer a edição crítica de Raizes do Brasil (da qual ambos foram os organizadores). Estavam os dois algo embaraçados, "porque a edição no fundo vai contra a famosa interpretação que ele fez do amigo Sérgio Buarque”. Surpreendentemente, Candido teria vibrado com o iconoclasmo da dupla; disse-lhes, na ocasiáo, "com todas as letras, que afinal talvez houvesse um pouco de exagero na sua interpretação". Contudo, à parte a nobreza com que recebia aquele presente de grego, por assim dizer, impressionou a Monteiro o teor de uma inconfidência que lhes contaria após um prelúdio meio epistêmico.

Ele nos disse primeiro que a literatura organiza as ideias, a música organiza a sensibilidade, enquanto as artes plásticas organizam a maneira de ver o mundo. Isto para contar, tão vividamente que nos comovemos, a cena, em que ele e Dona Gilda visitaram o amigo historiador, Sérgio Buarque de Holanda, já muito doente, às portas da morte. Sérgio não dizia coisa com coisa, e Candido nos conta que se perguntou então se eles tinham o direito, a despeito da intimidade, de estar ali e vê-lo naquele estado, a delirar. Mas eis que, de um golpe, Sérgio se levanta com seu chambre e começa a declamar a célebre oitava de Camões: "No mar tanta tormenta, e tanto dano,/ Tantas vezes a morte apercebida!/ Na terra tanta guerra, tanto engano,/ Tanta necessidade avorrecida!/ Onde pode acolher-se um fraco humano,/ Onde terá segura a curta vida,/ Que não se arme, e se indigne o Céu sereno/ Contra um bicho da terra tão pequeno?". Candido a declama também, para ao fim nos dizer: a literatura lhe deu um último momento de lucidez (Monteiro, 2017).

Para além de qualquer outro sentido possível, a história acima tem o condão de revelar que, até mesmo no instante em que se viu decisivamente confrontado com a antítese de sua clássica exegese, Antonio Candido se mostrou (ou foi exibido) mais uma vez como aquele "que sabe uma porção de coisas que ninguém sabe"; feito o senex junguiano, arquétipo do velho sábio encarnado, "uma espécie de criador de mitos e fornecedor de rumos", segundo uma impressão de Afonso Arinos de Melo Franco (1981, p. 102), não por acaso a respeito do então jovem graduando em direito Sérgio Buarque de Holanda. Elementar, meu caro. 


\section{Referências Bibliográficas}

Barbosa, Francisco de Assis. (1988), “Introdução”. In: Barbosa, Francisco de Assis (org.). Raizes de Sérgio Buarque de Holanda. 2 ed. Rio de Janeiro, Rocco.

Barros, Jayme de. (1937), “Conceito de civilização brasileira”. Diário da Noite, seção Espelho dos Livros, p. 2. Disponível em: http://memoria.bn.br/DocReader/221961_01/30951, consultado em 25/3/2019.

Barros, Jayme de. (1936), "Raízes do Brasil". Diário da Noite, seção Espelho dos Livros, p. 2. Disponível em: http://memoria.bn.br/DocReader/221961_01/30951, consultado em $25 / 3 / 2019$.

BATE, Walter Jackson. (1977), Samuel Johnson. Nova York, Harcourt Brace Jovanovich.

Benjamin, Walter ([1938] 2002), Selected Writings: Volume 3 (1938-1940). Cambridge/ Londres, The Belknap Press of Harvard University Press.

Bourdieu, Pierre. (2004), Coisas ditas. Tradução de Cássia R. da Silveira e Denise Moreno Pegorim. São Paulo, Brasiliense.

Candido, Antonio. (1998), “A visão política de Sérgio Buarque de Holanda”. In: Candido, Antonio. (org.). Sérgio Buarque de Holanda e o Brasil. São Paulo, Fundação Perseu Abramo, pp. 81-88.

CAndido, Antonio. ([1962] 2000), “Prefácio da 2a edição”. Formação da literatura brasileira: momentos decisivos. Belo Horizonte, Itatiaia, vol. 1.

Candido, Antonio. (2006), Literatura e sociedade. Rio de Janeiro, Ouro sobre Azul.

CAndido, Antonio. (2005), Literatura e sociedade. Direção, roteiro e produção de Marcia Coutinho R. Jimenez. São Paulo. Disponível em https://youtu.be/0ygzd0gIyGg?t=670, consultado em 18/4/2019.

Candido, Antonio. (1983), “Minha amizade com Sérgio”. Revista do Brasil, Rio de Janeiro, $3(6): 132-133$.

Candido, Antonio. ([1967] 2016), “O significado de Raizes do Brasil”. In: Holanda, Sérgio Buarque de. Raizes do Brasil. Organização de Pedro Meira Monteiro e Lilia Moritz Schwarcz. São Paulo, Companhia das Letras, pp. 351-369.

Candido, Antonio. ([1986] 2016), “Prefácio”. In: Holanda, Sérgio Buarque de. Raizes do Brasil. Organização de Pedro Meira Monteiro e Lilia Moritz Schwarcz. São Paulo, Companhia das Letras, pp. 351-353.

Candido, Antonio. (1990), "Radicalismos”. Estudos Avançados, 4 (8): 4-18. Disponível em http://www.revistas.usp.br/eav/article/view/8540.

Candido, Antonio. (1993), Recortes. São Paulo, Companhia das Letras.

Candido, Antonio. (1982), "Sérgio em Berlim e depois". Novos Estudos Cebrap, I (3): 4-9.

CAndido, Antonio. (1988), “Sérgio, o radical”. In: SÉRGIO BUARQUE de Holanda: vida e obra. São Paulo, Instituto de Estudos Brasileiros. 
CAndido, Antonio. (2002), Textos de intervenção. Seleção, apresentação e notas por Vinícius Dantas. São Paulo, Livraria Duas Cidades (col. Espírito Crítico).

Carvalho, Raphael Guilherme de. (2015), “A escrita de si de Sérgio Buarque de Holanda nos anos 1970 (notas para estudo)”. Tempos Históricos, 19: 103-119.

"Conflito NUm BAR: muita pancadaria e três pessoas feridas, uma das quais gravemente". (1934), Jornal do Brasil, seção Na Polícia e nas Ruas, p. 13. Disponível em http://memoria. bn.br/DocReader/030015_05/45899, consultado em 18/1/2019.

Costa, Emília Viotti da. (2015), Brasil: história, textos e contextos. São Paulo, Edusp.

EugÊnio, João Kennedy. (2016), "Entre totem e tabu: o processo de Raizes do Brasil”. In: Holanda, Sérgio Buarque de. Raizes do Brasil. Organização de Pedro Meira Monteiro e Lilia Moritz Schwarcz. São Paulo, Companhia das Letras, pp. 431-438.

Eugênio, João Kennedy. (2011), Ritmo espontâneo: organicismo em Raízes do Brasil de Sérgio Buarque de Holanda. Teresina, EdufPI.

Feldman, Luiz. (2016), Clássico por amadurecimento: estudos sobre Raízes do Brasil. Rio de Janeiro, Topbooks.

Franco, Afonso Arinos de Melo. (1981), “Entrevista”. In: Mota, Lourenço Dantes Mota (org.). A História vivida: documentos abertos. São Paulo, O Estado de São Paulo.

Furtado, André Carlos. (2014), As edições do cânone: da fase buarqueana na coleção História Geral da Civilização Brasileira (1960-1972). Rio de Janeiro, Eduff.

GASPARI, Elio. (1994), “Uma cabeça que bate contra a maré: Wanderley Guilherme dos Santos, elitista e marginal, vencedor de causas perdidas”. Revista Veja, n. 1340: 40-43.

Gay, Peter. (1978), A cultura de Weimar. Tradução de Laura Lúcia da Costa Braga. Rio de Janeiro, Paz e Terra.

GaY, Peter. (1990), O estilo na história. São Paulo, Companhia das Letras.

Gontijo, Rebeca \& Franzini, Fábio. (2009), “Memória e história da historiografia no Brasil: a invenção de uma moderna tradição, anos de 1940-1960". In: SoIHET, Rachel et al. (orgs.). Mitos, projetos e práticas politicas: memória e historiografia. Rio de Janeiro, Civilização Brasileira.

GuSFIELD, Joseph R. (1981), The culture of public problems: drinking, driving and the symbolic order. Chicago/Londres, University of Chicago Press.

Hallewell, Laurence (2017), O livro no Brasil: sua história. 2 ed. São Paulo, Edusp.

Holanda, Sérgio Buarque de. (2004), "Corpo e alma do Brasil: Entrevista de Sérgio Buarque de Holanda”. Novos Estudos Cebrap, 69: 3-14.

Holanda, Sérgio Buarque de. (1996), O espírito e a letra: estudos de crítica literária, 19481959: vol. II. Organização de Antonio Arnoni Prado. São Paulo, Companhia das Letras.

Holanda, Sérgio Buarque de. ([1936] 2016), Raizes do Brasil. Organização de Pedro Meira Monteiro e Lilia Moritz Schwarcz. São Paulo, Companhia das Letras.

Holanda, Maria Amélia Buarque de. ([1979] 2006), “Apontamentos para a cronologia de 
Sérgio Buarque de Holanda”. In: Holanda, Sérgio Buarque de. Raizes do Brasil. Organização de Ricardo Benzaquen de Araújo e Lilia Moritz Schwarcz. São Paulo, Companhia das Letras, pp. 421-446.

Johnson, Randal. (1995), “A dinâmica do campo literário (1930-1945)”. Revista USP, (26): 164-181.

Kermode, Frank. (1979), "Institutional control of interpretion”. Salgamundi, 43: 72-86.

Konder, Leandro. (1991), Intelectuais brasileiros e marxismo. Belo Horizonte, Oficina de Livros.

LEÃo, Múcio. (1936), "Registro Literário". Jornal do Brasil, Rio de Janeiro, p. 8.

LeITE, Dante Moreira. (2002), O caráter nacional brasileiro: história de uma ideologia. 8 ed. São Paulo, Edusp.

Lima, Hermes. Notas à vida brasileira. São Paulo, Brasiliense, 1945.

LukÁcs, György. (2018), O jovem Hegel: e os problemas da sociedade capitalista. São Paulo, Boitempo.

Mata, Sérgio da. (2016), “Tentativas de desmitologia: a revolução conservadora em Raízes do Brasil”. Revista Brasileira de História, 36 (73): 63-87.

Matos, Júlia Silveira. (2008), "A Revolução de 1930, os intelectuais e as críticas ao personalismo: heranças da tradição do pensamento político brasileiro”. XIX Encontro Regional de História - ANPUHRS. Poder, violência e exclusão. São Paulo, Edusp.

Matos, Júlia Silveira. (2006), "O intelectual e a obra Raizes do Brasil: uma discussão historiográfica”. Biblos: Revista do Departamento de Biblioteconomia e História, vol. 19, pp. 151-170.

Mello e Souza, Laura de. (2014), “Prefácio: estrela de uma vida inteira”. In: Holanda, Sérgio Buarque de. Monções. São Paulo, Companhia das Letras, pp. 15-37.

Mendes, Oscar. (1937). "Raízes do Brasil”. Folha de Minas, seção A Alma dos Livros. Disponível em: pasta 61, série Produção de Terceiros, Álbum de Resenhas sobre Raizes do Brasil, preparo de Cecília Buarque de Holanda, entre 1936 e 1938. siarQ/Unicamp Fundo Sérgio Buarque de Holanda. Consultado em 27/09/2018.

Monteiro, Pedro Meira. (2018), “A necessária clareza de Antonio Candido”. Revista Maracanan, 18: 13-17.

Monteiro, Pedro Meira. (2017), “Literatura contra a morte”. Disponível em https://meiramonteiro.com/literatura-contra-a-morte/, consultado em 15/2/2019.

Monteiro, Pedro Meira. (org.). (2012), Mário de Andrade e Sérgio Buarque de Holanda: Correspondência. São Paulo, Companhia das Letras/Instituto de Estudos Brasileiros; Edusp. Monteiro, Pedro Meira \& Schwarcz, Lilia Moritz. (2016), “Uma edição crítica de Raízes do Brasil: o historiador lê a si mesmo". In: Holanda, Sérgio Buarque de. Raizes do Brasil. Organização de Pedro Meira Monteiro e Lilia Moritz Schwarcz. São Paulo, Companhia das Letras.

Nicodemo, Thiago Lima. (2018), "Antonio Candido e Sérgio Buarque de Holanda”. Revista USP (118): 105-116. Disponível em https://doi.org/10.11606/issn.2316-9036.v0i118p105-116. Nicodemo, Thiago Lima. (2016), “Para além de um prefácio: ditadura e democracia no diá- 
logo entre Antonio Candido e Sérgio Buarque de Holanda”. Revista Brasileira de História, 36 (73): 159-180.

Perrone-Moisés, Leyla. (1998), Altas literaturas: escolha e valor na obra critica dos escritores modernos. São Paulo, Companhia das Letras.

Ribeiro, Douglas Carvalho. (2018), As raizes antiliberais de Sérgio Buarque de Holanda: Carl Schmitt em Raízes do Brasil. Rio de Janeiro, Lumen Juris.

Ringer, Fritz. (2002), O declinio dos mandarins alemães: a comunidade acadêmica alemã (1890-1933). São Paulo, Edusp.

Rocha, João Cezar de Castro. (2004), O exilio do homem cordial. Rio de Janeiro, Museu da República.

Rocha, João Cezar de Castro. (2012a), "Raizes do Brasil: biografia de um livro-problema”. In: Marras, Stélio (org.). Atualidade de Sérgio Buarque de Holanda. São Paulo, Edusp/ Instituto de Estudos Brasileiros.

Rocha, João Cezar de Castro. (2012b), “Sérgio Buarque e Gilberto Freyre: Raízes de uma rivalidade literária”. Dictaぬ Contradicta, 9, Rio de Janeiro, Civilização Brasileira.

SAInte-Beuve, Charles Augustin. (2013), “O que é um clássico?”. Tradução de Osvaldo Manuel Silvestre. Revista de Estudos Literários, 3: 343-358.

Sanches, Rodrigo Ruiz. (2011), "Sérgio Buarque de Holanda na UsP". Revista Sociedade e Estado, 26 (1): 241-259.

Santos, Nelson Pereira dos. (2004), Raizes do Brasil: uma cinebiografia de Sérgio Buarque de Holanda. Direção de Nelson Pereira dos Santos. Rio de Janeiro, Regina Filmes, Videofilmes, Riofilmes.

Vainfas, Ronaldo. (2010), "Posfácio". In: Holanda, Sérgio Buarque de. Visão do Paraíso: os motivos edênicos no descobrimento e colonização do Brasil. São Paulo, Companhia das Letras, pp. 551-560.

Viотті, Emília. (2015), Brasil: história, textos e contextos. São Paulo, Edusp.

Waizbort, Leopoldo. (2007), A passagem do três ao um. São Paulo, Cosac Naify.

WAizbort, Leopoldo. (2002), “Esquema (parcial) de Antonio Candido”. Novos Estudos Cebrap, 64: 177-188.

WAizbort, Leopoldo. (2016), “Inércia e Transformação Lenta”. In: Holanda, Sérgio Buarque de. Raizes do Brasil. Organização de Pedro Meira Monteiro e Lilia Moritz. São Paulo, Companhia das Letras.

WAizbort, Leopoldo. (2011), “O mal-entendido da democracia: Sérgio Buarque de Holanda, Raízes do Brasil, 1936”. Revista Brasileira de Ciências Sociais, 26 (76): 39-62.

ŽıžEK, Slavoj. (2012), Vivendo no fim dos tempos. São Paulo, Boitempo. 


\section{Resumo}

Elementar: Antonio Candido, inventor do inventivo Sérgio Buarque de Holanda

Ao reconstituir, com base em diversas fontes documentais (inclusive inéditas, ao que consta), a longa relação de camaradagem entre Antonio Candido e Sérgio Buarque de Holanda, discorre-se, no presente artigo, sobre o papel daquele crítico literário para a ulterior afirmação de Raízes do Brasil no cenário das ideias brasileiras. Conclui-se que a amizade entre ambos os intelectuais foi decisiva para a sagração desse livro - e, decerto, a de seu autor - como clássico da literatura nacional não ficcional.

Palavras-chave: Antonio Candido; Sérgio Buarque de Holanda; Raizes do Brasil; Biografia; Clássico.

\section{Abstract}

Elementary: Antonio Candido, inventor of the inventive Sérgio Buarque de Holanda

By a partial and mainly bibliographical reconstruction of the long relationship between Antonio Candido e Sérgio Buarque de Holanda, one discusses in this article about the role of that literary critic for the further affirmation of Raizes do Brasil in the Brazilian ideas' scenario. It is concluded that the friendship between both intellectuals was decisive for the consecration of the book and his author, certainly, as a classic of the national non-fictional literature.

Keywords: Antonio Candido; Sérgio Buarque de Holanda; Raizes do Brasil; Biography; Classical book.

Texto recebido em 19/1/2020 e aprovado em 9/4/2020.

DOI: 10.11606/0103-2070.ts.2020.165804.

Vinícius Madureira Maia é doutorando vinculado ao Programa de Pós-graduação em Sociologia da Universidade de São Paulo (PPGS-USP). E-mail: vi.madureira@gmail.com Kadma Marques Rodrigues é professora permanente do Programa de Pós-graduação em Sociologia da Universidade Estadual do Ceará (pPGs-Uece). 